\title{
PONTOS COMUNS E HETEROGENEIDADE DAS CULTURAS POLÍTICAS NOS PALOPS
}

\author{
- Um ponto de vista "pós-póscolonial"-1 \\ Michel Cahen*
}

\begin{abstract}
RESUMO
Nas interpretações da evolução dos PALOPs, muitas vezes o que foi feito, em particular por académicos de esquerda, corresponde exatamente ao que os autores pioneiros dos estudos subalternos na Índia censuravam aos autores próximos do nacionalismo modernista do Partido do Congresso ou do marxismo estalinizado do Partido comunista da Índia: a saber, uma hipertrofia do papel dos discursos, do papel das elites em via de globalização e uma desvalorização das expressões das subalternidades. Além disso, se muitos artigos, teses, e livros em ciências sociais sobre e nos países de língua portuguesa incluíram frequentemente nos seus títulos a palavra "pós(-)colonial" a partir dos finais do século xx, na grande maioria dos casos, o sentido foi meramente cronológico ("pós-colonial"), sem ligação com uma aproximação teórica "póscolonial". Mas também se deve evitar a essencialização da herança colonial trazida pela teoria póscolonial, que subestima os processos contemporâneos de produção da subalternidade, sem os quais essas heranças coloniais perderiam rapidamente a sua relevância em certos estratos sociais.

Neste contexto, o objetivo deste artigo é desenvolver uma análise subalternista mas "pós-póscolonial" da evolução dos PALOPs, relativizando o papel do discurso político das elites no poder, para dar prioridade à evolução das formações sociais, e, neste quadro, voltar a analisar o
\end{abstract}

*Université de Bordeaux, Sciences Po Bordeaux Unité mixte de recherche n 5115 "Les Afriques dans le monde", CNRS/Sciences po Bordeaux, <m.cahen@sciencespobordeaux.fr>

1 A versão preliminar deste artigo foi lida como comunicação no Colóquio «África XXI: Literatura, Cultura, Sociedade nos Países Africanos de Língua Portuguesa ", organizado pelo Departamento de Português da Faculdade de Letras da Eötvös Loránd Tudományegyetem e pela Associação Internacional dos Lusitanistas, nos dias 11 e 12 de novembro de 2013, Budapeste, Hungria. Agradeço à Bárbara dos Santos pela releitura e edição do texto. 
"conteúdo social" da cultura política manifestada pelo discurso. Além disso, é necessário considerar a grande diversidade dos PALOPs, que são países bem mais inseridos na história das suas regiões respectivas do que "ex-portugueses".

\begin{abstract}
Many times, what has been done when interpreting the evolution of the PALOPs, especially by academics from the left-wing, corresponds exactly to what the pioneering authors of subaltern studies in India censured, in the authors close to modernist nationalism of the Congress Party, or close to Stalinized Marxism of the Communist Party in India. Thereby meaning a hypertrophy in the speech role, in the role of the elites on the way to globalization and a devaluation in the subalterns' expressions. Furthermore, if so many articles, thesis' and social sciences' books on and from Portuguese speaking countries frequently have included, from the end of the XX century onwards, the word "post(-)colonial" in their titles, most of the times the meaning was merely chronological ("post-colonial"), without any links to a theoretical "postcolonial" approach. But also, the essentialisation of colonial heritage brought by postcolonial theory should be avoided, as it underestimates the contemporary production of subalternity, without which these colonial heritages would rapidly lose their relevance in some social spheres.

In this context, this article's objective is to develop a subaltern analysis of the PALOPs evolution, but in a"post-postcolonial" way, putting in perspective the role of the political discourse of the ruling elites, in order to give priority to the evolution of social structures, and within this framework, come back to analyzing the "social content" of the political culture which appears throughout the discourse. However, the important diversity of the PALOPs is to bear in mind, since they are countries far more shaped by their regions' African history than by an "ex-Portuguese" identity.
\end{abstract}

Palavras-chave: PALOPs - cultura política - póscolonial - crioulidade - partido único - subalternidade - nação 
Embora se encontre na continuidade de trabalhos desenvolvidos há vários anos sobre a evolução política dos Países Africanos de Língua Oficial Portuguesa (PALOPs), este artigo insere-se mais precisamente num projeto de pesquisa de crítica à crítica pós(-)colonial ${ }^{2}$, ou seja, uma pesquisa para o desenvolvimento de uma crítica "pós-póscolonial", nas ciências sociais ${ }^{3}$. Sabe-se que, na genealogia do pós-colonial, houve em primeiro lugar uma teoria literária. Tal como no mundo dito francófono mas provavelmente por razões diferentes, essa penetrou tardiamente $o$ mundo dito lusófono, seja ele português, brasileiro ou africano: começou talvez pelas "margens", isto é, pelos estudos lusófonos desenvolvidos na Holanda, na Inglaterra, nos Estados Unidos (frequentemente por pesquisadores de origem portuguesa ou brasileira) mais do que nos próprios países; mas depois manifestou-se neles com algumas especificidades, em particular nas ciências sociais ${ }^{4}$. De qualquer forma, não é de admirar que haja diferenças entre um país como o Brasil que é independente desde 1822 mas que se pode caracterizar como uma "auto-colónia" soberana ${ }^{5}$ e a sua antiga metrópole que perdeu as suas últimas colónias em 1975. No caso de Portugal, por exemplo, pode-se falar da influência

2 Explico infra o porquê dessas ortografias estranhas, "póscolonial", "pós-colonial" e "pós(-)colónial".

3 Ver os trabalhos do Ateliê internacional "Pós colonialismo? Conhecimento e política dos subalternos", de 17 a 19 de setembro de 2013, Universidade de São Paulo, Departamento de sociologia, Programa de pós-graduação em sociologia, Centro de estudos dos direitos da Cidadania, em via de publicação.

4 Chama-se a atenção sobre o facto que este artigo incide somente sobre as ciências sociais.

5 No Brasil, a Revista de estudos antiutilitaristas e póscoloniais foi fundada somente em janeiro de 2011 por académicos de Pernambuco e Alagoas, isto é, da "periferia” brasileira, o que talvez não seja por acaso. Ela "é um veículo digital de divulgação semestral que nasce voltada para a ampliação do debate antiutilitarista [...], a partir da incorporação das críticas poscoloniais e descoloniais que vêm progredindo na América Latina em sintonia com movimentos intelectuais e culturais que ocorrem em paralelo na África, na Ásia, na Europa e na América do Norte" (<http://www.revista-realis.org $>$ ). 
do sociólogo português Boaventura de Sousa Santo que passou, na viragem do século XXI, do pós-modernismo ao pós-colonial ${ }^{6}$. Não há espaço aqui para discutir essas possíveis especificidades ${ }^{7}$ mas queria, no entanto, assinalar um problema.

É conhecido o parentesco entre os estudos póscoloniais que se desenvolveram a partir do extremo fim dos anos 80 na Austrá$\mathrm{lia}^{8}$, e os estudos subalternos que começaram dez anos mais cedo em Bengala (Guha 1983, Merle 2004). Nesse Estado da Índia, os estudiosos subalternistas quiseram dar toda a atenção aos estratos sociais que o nacionalismo modernista do Partido do Congresso ou o marxismo estalinizado do Parti comunista da Índia consideravam, de maneira paternalista, como atrasados ou como elementos de desenvolvimento de uma resistência anticolonial "pré-política"; tratava-se neste caso das revoltas na casta dos Intocáveis e do movimento dos Naxalitas. Os estudos subalternos reconstruíram a dignidade política desses estratos sociais como atores plena e politicamente conscientes da modernidade, mesmo que fosse uma modernidade diferente. Também notaram que um certo conhecimento produz subalternidade, mas que os subalternos produzem conhecimento, quaisquer que sejam as suas dificuldades em "falar" (Spivak 1988)9. Embora os fundadores dos estudos subalternos não tivessem sempre reivindicado o póscolonial $^{10}$, na prática, as

6 ... tal como ele próprio o explicou na conferência de abertura do Congresso afro-luso-brasileiro de Ciências sociais, Coimbra, 2004. B. de Sousa Santos considera-se mais exatamente como um "pós colonial de oposição".

7 Para uma primeira discussão, ver o artigo introdutivo de Morier-Genoud \& Cahen (2012: 1-28)

8 Ver o famoso livro The Empire Writes Back (Ashcroft, Griffiths \& Tiffin 1989)

9 Salvo erro da minha parte, a primeira edição de Spivak em português só foi publicada passado doze anos (Spivak 2010).

${ }^{10}$ No texto onde anuncia o fim dos estudos subalternos, P. Chatterjee quase nunca fala do póscolonial (Chatterjee 2012). 
suas análises foram mais ou menos "fundidas" na grande nuvem póscolonial pela geração académica que se apropriou grosso modo dessa maneira de ver: de qualquer forma, tratava-se de sublinhar a capacidade de fala e de ação (agency) dos subalternos e a necessidade de vê-los com olhos não eurocêntricos.

Pois, voltando aos estudos em ciências sociais sobre e nos países de língua portuguesa, pode-se facilmente constatar que muitos artigos, teses, e livros incluíram frequentemente nos seus títulos a palavra "pós(-)colonial" ou, mais raramente, "subalterno" a partir dos finais do século Xx. No entanto, na grande maioria dos casos, o sentido é meramente cronológico ${ }^{11}$. Até quando o título leva a pensar numa teorização diferente, na prática não é o que acontece: conteúdos que, dez anos mais cedo, não incluiriam o vocábulo "pós(-)colonial" continuam quase iguais. Muitas vezes aparece o vocábulo, mas com ou sem ele, o conteúdo ${ }^{12}$ fica idêntico ${ }^{13}$.

${ }^{11}$ Tomando só em consideração os estudos sobre os PALOPs, sobre os quais vou me debruçar, ver por exemplo os títulos A History of Postcolonial Lusophone Africa, (Chabal 2002), The State against the peasantry. Rural Struggles in Colonial and Postcolonial Mozambique, (Bowen 2000), Revolution, Counter-Revolution and Revisionism in Postcolonial Africa. The case of Mozambique, 1975-1994, (Dinerman 2006), L'Angola postcolonial. (Messiant 2008, 2009). No caso de C.Messiant, foi o editor que impôs a grafia francesa "postcolonial" em vez de "post-colonial".

12 ... pelo menos o conteúdo empírico, depois de uma possível parte teórica inicial reivindicando-se do póscolonial.

${ }^{13}$ Um bom exemplo seria o livro Pós-Colonialismo e identidade (Rosa \& Castillo 1998), onde nem se encontra uma ponta de teoria póscolonial, com a exceção da conclusão, em inglês e publicada separadamente, de Patrick Chabal (1998). No caso brasileiro, excetuando a grande maioria dos casos onde "pós(-)colonial" é utilizado no sentido meramente cronológico (veja infra), é de reparar que, muitas vezes, os trabalhos realmente relativos à teoria póscolonial incidem sobre obras de língua inglesa: tais como Souza (1992) sobre o discurso literário pós-colonial em língua inglesa, um dos trabalhos mais precoce; Monteiro (1999), que é uma recensão de H. Bhabha; Costa (2001), que é uma resenha de E. Saïd; Monteiro (2009), sobre literaturas de língua inglesa; etc. 
Com efeito, reina a confusão mais completa entre, por um lado, o que é pós-colonial/póscolonial (em francês com traço, em português com traço ou espaço), ou seja, uma situação que julgamos ser (ou que é principalmente) herdeira da situação colonial, como houve pós-guerras, pós-fascismos, pós-estalinismos, pós-fordismos em vários países, no sentido cronológico da expressão; e por outro lado o que é póscolonial (e eu sugiro que seja sem traço nem espaço), no sentido de uma acepção que não se refere a uma situação mas antes a uma análise que consegue ir além das heranças epistemológicas coloniais -um "pós", com certeza, mas que se situa ao nível do raciocínio e não do tempo: a análise é que é póscolonial, independentemente da situação analisada. Os autores póscoloniais serão unânimes em dizer que a definição correta é a segunda. Assim, a abordagem póscolonial pode estudar questões pré-coloniais, coloniais ou "pós-coloniais com traço". Em princípio, está tudo claro...

Só que os mesmos autores que dão essa definição, esses mesmos, vão de imediato falar em "França pós(-)colonial", "Portugal pós(-)colonial", "ruptura pós(-)colonial", "situação pós(-)colonial"14! Ora, a expressão "situação pós-colonial” (mesmo com traço) refere-se necessariamente ao artigo fundador de Georges Balandier, "La situation coloniale" (1951). Mas será que é possível estabelecer um paralelismo "situação colonial/situação pós-colonial"? No caso de Balandier, tratava-se de descrever e de entender a sociedade indígena sob dominação colonial, de descrever a situação de uma sociedade inteira, enquanto que o póscolonial é (ou devia ser) uma abordagem específica de assuntos coloniais ou pós-coloniais (aqui no sentido elementar de posterioridade), ou até de outros assuntos

\footnotetext{
${ }^{14}$ Escrevo aqui "pós(-)colonial" com traço entre parênteses porque em francês o termo que aparece quase sempre é postcolonial, em vez de post-colonial, o que agrava a confusão. Em inglês o postcolonial é quase generalizado. Em francês, escrevo postcolonial quando se trata da teoria e post-colonial quando se trata da situação cronológica. Sugiro a mesma distinção em português, "póscolonial" (teoria) e "pós colonial" ou "pós-colonial" (situação).
} 
(imaginários nacionais, relações sociais de sexo, etc.). Se aceitarmos o paralelismo "situação colonial/situação pós-colonial", isso significa que consideramos que, numa sociedade inteira, pode haver uma "situação pós colonial” (por exemplo "Portugal pós-colonial", "Brasil pós-colonial"), e neste caso a "pós-colonialidade" seria o conceito para exprimir a realidade desta sociedade ${ }^{15}$. Será Portugal, enquanto sociedade, uma sociedade pós-colonial? Para as sociedades africanas descolonizadas há cinquenta anos, depois de uma colonização de cem anos, já é assaz discutível. Embora Portugal seja obviamente "pós-colonial" no sentido cronológico do termo porque perdeu as suas colónias, falar de uma "situação pós-colonial" significa que essa herança é o elemento (ou mesmo um dos elementos) essencial de estruturação contemporânea da sua sociedade. Ora isso não é nem mais nem menos do que uma reificação, até uma essencialização, das heranças e das memórias, que subestima fortemente a produção contemporânea de discriminações ${ }^{16}$. Por exemplo, é a mesma produção contemporânea de subalternidade que provocou a permanência das imigrações africanas, e o desenvolvimento das imigrações ucraniana e brasileira em Portugal. Com certeza, a parte africana da imigração está ligada à história colonial portuguesa, mas fundamentalmente, além de óbvias nuances entre essas imigrações, trata-se do mesmo fenómeno ligado à etapa atual do sistema-mundo capitalista e não

${ }^{15}$ É de notar aqui que o conceito de "colonialidade" incluído na dita "pós-colonialidade" já não corresponde em nada ao sentido dado por Aníbal Quijano quando inventou este conceito. Para Quijano, a colonialidade é a situação atual dos países de América Latina (que podemos alargar à África e à Ásia do Sul), pelo que "pós-colonialidade" acabaria por dizer que já não há colonialidade! O conceito de colonialidade foi apresentado pela primeira vez por Aníbal Quijano em 1992 (1992a, 1992b).

16 Esses dois parágrafos sobre a confusão em torno do conceito de pós(-)colonial são oriundos, de maneira bastante resumida, da minha comunicação "O que pode ser e o que não pode ser a colonialidade?", no Ateliê internacional "Pós colonialismo? Conhecimento e política dos subalternos", Universidade de São Paulo-FFLCH-Departamento de sociologia-PPGS, Cenedic, 17-18-19 de setembro de 2013. [a sair nos Cadernos CRH, Salvador da Bahia, 2014] 
são o produto de uma estrutura "pós-colonial" de toda a sociedade ${ }^{17}$. Se a memória colonial perdura enquanto memória em alguns estratos sociais, é porque quadros sociais existem para tal (Halbwachs 1994), e esses quadros sociais são contemporâneos.

\section{Palavras radicais, análises pré-subalternas?}

Pois, será que os PALOPs têm sociedades pós-coloniais, isto é, sociedades principalmente estruturadas pela herança colonial, ou serão elas, depois da transição, o produto contemporâneo do capitalismo periférico? Obviamente, para essas descolonizações que, com as únicas exceções de Djibuti, do Zimbabué e da África do Sul, foram as mais tardias de África, haverá uma mistura, com uma herança ainda "pesada", porém, devido mais precisamente à sua reprodução no contexto do capitalismo periférico do que a uma mera continuidade. Mas mesmo assim, se quisermos ser fiéis ao espírito dos Subaltern Studies e da Postcolonial Theory ${ }^{18}$, temos que prestar mais atenção específica aos subalternos, ou num sentido mais lato, aos processos de produção de marginalidade na sociedade como um todo, e, num sentido ainda mais lato, à evolução da estrutura social e das formações sociais no período pós-independência. Por outras palavras, mesmo se analizarmos as elites, teremos que o fazer no seu posicionamento, no conjunto das formações sociais de uma dada sociedade e nas suas trajetórias históricas. Será que é isso que a historiografia dominante nos anos 1975-1990 e mesmo depois fez?

Penso que não. Obviamente, houve estudos de caso. Mas, ao nível das interpretações mais globais da evolução desses países,

${ }^{17}$ Como foi dito em francês, "Les Arabes sont des Italiens comme les autres” («Os Árabes são Italianos como quaisquer outros»)).

${ }^{18}$ Não me debruço aqui sobre a parte das análises póscoloniais mais fortemente influenciadas pela teoria pós-moderna. 
penso que muitas vezes o que foi feito, frequentemente por académicos de esquerda em particular, corresponde exatamente ao que os autores pioneiros dos estudos subalternos na Índia censuravam aos autores próximos do nacionalismo modernista e burguês do Partido do Congresso ou do marxismo estalinizado do partido comunista da Índia: a saber, uma hipertrofia do papel dos discursos, do papel das elites em via de globalização e uma desvalorização das expressões das subalternidades e marginalidades (e, nessas últimas, uma sobrevalorização discursiva da classe operária "moderna"). É verdade que, no caso dos PALOPs, houve um contexto geopolítico que ajudou a deslegitimação das marginalidades, ligado ao facto da África do Sul do apartheid apoiar e manipular essas expressões de marginalidades (como a Unita e a Renamo em Angola e Moçambique ${ }^{19}$ ). No entanto, nas tentativas de análises das razões pelas quais partes do campesinato apoiavam as rebeliões, nota-se que muitas vezes a legitimidade só foi reconhecida ao partido no poder porque era ele que tinha alcançado a descolonização enquanto movimento de libertação, qualquer que tenha sido a sua atividade depois, enquanto partido único. Como o discurso era "marxista-leninista" ou de uma variante próxima ("democracia revolucionária"), os países foram analisados como "socialistas" ou, pelo menos num "rumo ao socialismo", sem análise das formações sociais reais, hipertrofiando, pois, o papel do discurso e das elites modernizadoras. Isso continua hoje em dia: quantas vezes podemos ler em publicações atuais, a respeito dos anos 1975-1990, expressões tais como: "a fase socialista", "o período socialista", etc.? E quando esse dito "socialismo" ou esse dito "rumo" se transformou num neoliberalismo e num capitalismo selvagem, isso foi explicado pelo facto do projeto socialista ter sido "vencido", isto é, devido a razões exteriores e não a causas internas oriundas do sistema de partido único do corpo social burocrático no poder. Uma derrota estranha, que vê os partidos "vencidos" ficarem no poder para fazer,

${ }^{19}$ Unita: União nacional para a independência total de Angola; Renamo: Resistência nacional de Moçambique. 
oficialmente, o contrário do que advogavam poucos anos atrás ${ }^{20}$. Ainda chegaram a ser caracterizados positivamente pelos académicos de esquerda acima citados, já não como "socialistas", mas como sendo os "únicos partidos verdadeiramente nacionais" nos princípios da fase neoliberal, o que significava que os fenômenos de oposição só podiam ser etno-tribalistas e não "nacionais".

Já agora, queria esclarecer um ponto muito importante: quando disse que, muitas vezes, o papel do discurso político foi sobrestimado nas análises sobre os PALOPs dos "anos radicais", não quis dizer com isso que esse discurso não tem importância. $\mathrm{O}$ discurso tem uma grande importância. Mas o que foi uma sobrestimação encontra-se no estabelecimento de uma relação mecânica de causa e efeito: o discurso era socialista, pois o sistema era socialista. Ao contrário, o discurso político é muito importante, enquanto ferramenta de estruturação da elite: é o que lhe permite definir aos seus próprios olhos a sua legitimidade e o seu papel histórico. Ele é a "ideologia falada" ${ }^{21}$, a expressão de um habitus e de uma cultura historicamente produzida. Porém, a análise do discurso deve ser integrada à análise das formações sociais realmente existentes, e não se substituir a ela. Se se proceder assim, já não haverá nenhuma contradição entre o facto de reconhecer a particularidade da reivindicação "marxista-leninista" em Angola e Moçambique ou da "democracia revolucionária" em

\footnotetext{
${ }^{20}$ Hoje em dia, Angola está a atrair a maioria dos trabalhos académicos, mas é um fenómeno completamente novo. Durante vários anos, a partir de 1975 e até 20082010, a maioria dos artigos e dos livros eram sobre Moçambique, seguido de Cabo Verde, um país bem representado se considerarmo-lo proporcionalmente à sua modéstia territorial. Houve uma discussão interessante sobre este desequilíbrio na rede H-Luso-Africa em 2013. Para não ter que citar aqui a vasta historiografia das teses simpatizantes do "marxismo-leninismo" ou do "rumo ao socialismo" em Angola, Moçambique, Guiné, etc., permito-me remeter para um recente artigo meu sobre o tema (Cahen 2008).

${ }^{21}$ Utilizo o conceito de ideologia no sentido marxista tal como foi definido por Michael Löwy (1987).
} 
Cabo Verde, Guiné e São Tomé, e o facto de concluir que esses países permaneceram países capitalistas da periferia. É isso que explica a evolução ulterior, não como "derrota" imposta do exterior mas como resultado de uma transformação socialmente inscrita das elites no poder, que combina fatores internos e externos num mundo globalizado (Cahen 2010).

\section{Desejo social de partido único}

Assim, é frequente apresentar as evoluções das frentes de libertação ou partidos políticos que tomaram o poder nos PALOPs em 1974-1975 como sendo uma trajetória que começa com um "nacionalismo puro" no momento das fundações, que passa pelo "nacionalismo revolucionário", na época do alargamento das zonas libertadas e das primeiras crises internas nos fins dos anos sessenta, e pelo "marxismo-leninismo" nos casos de Angola e Moçambique e a "democracia revolucionária" nos casos da Guiné, de Cabo Verde e de São Tomé e Príncipe entre 1975 e 1977, para depois adotarem, segundo os países, entre 1983 e 1990, um nacional-liberalismo ainda dotado do sistema de partido único, antes de escolherem, a partir dos anos 1990, um nacional-liberalismo de conveniência pluralista. Essa descrição rápida está globalmente correta, mas muito mais para descrever os discursos do que para analisar a realidade, incluindo a realidade dos próprios partidos no poder. Só vou empregar um exemplo, paradigmático: parece lógico -pelo menos isso foi muito raramente questionado- pensar que o sistema de partido único nos PALOPs foi coerente com a adoção do marxismo-leninismo, isto é, que os movimentos vencedores implementaram o partido único porque eram marxistas-leninistas.

No entanto, essa maneira de ver levanta problemas consideráveis do ponto de vista da história e da sociologia política. Como já se sabe, em África, o partido único não foi de modo algum o apanágio 
dos partidos "marxistas-leninistas”, o que já impõe a necessidade de procurar uma razão comum aos partidos "marxistas-leninistas" e aos "anti-marxistas-leninistas" para encontrar uma explicação. Mesmo se nos restringirmos unicamente às colónias portuguesas de África, os grupos hostis à Frelimo, ao MPLA, ao PAIGC ou ao MLSTP 22 , não eram, por serem anti-marxistas, a favor do pluralismo político. Eram todos ${ }^{23}$ a favor do partido único e as suas lutas exprimiam uma concorrência para saber qual deles ia ser o partido único: foi óbvio durante a guerra civil angolana que começou antes da descolonização entre os três movimentos MPLA, FNLA e Unita ${ }^{24}$; e o mesmo pode-se dizer da rivalidade entre o PAIGC, a FLING e a UCID, ou, entre a Frelimo, a MANU e o Coremo ${ }^{25}$, antes e imediatamente depois da independência. A Frelimo reprimiu militarmente as tentativas paralelas de luta armada do Coremo. Isso não era só em nome da necessária unidade contra o colonizador, mas em função de uma cultura política que não imaginava a possibilidade de uma expressão pluralista da sociedade africana.

${ }^{22}$ Frelimo, Frente de libertação de Moçambique; MPLA: Movimento popiular de libertação de Angola; PAIGC: Partido africano para a independência da Guiné e Cabo Verde; MLSTP: Movimento de libertação de São Tomé e Príncipe.

23 ... pelo menos quase todos, além de ínfimos grupelhos. Basta lembrar a ala trotskista do PAIGC que era bastante importante de 1973 a 1979, e de que se podia pensar que era a melhor armada politicamente para imaginar um modelo político diferente do que o partido único. Apesar de ser teoricamente hostil ao princípio do partido único, acabou também de votar tacticamente a favor em 1975 na altura da tomada do poder pelo PAIGC em Cabo Verde. Obviamente, isso era "instrumental", para assegurar a permanência dela dentro do partido. Afinal, destruiu a sua visibilidade e não impediu a expulsão, que aconteceu em 1979.

${ }^{24}$ FNLA: Frente nacional de libertação de Angola; Unita: União nacional para a independência total de Angola.

${ }^{25}$ FLING: Frente de libertação para a independência nacional da Guiné; UCID: União Caboverdeana Independente e democrática; MANU: Mozambique African National Union ; Coremo: Comité revolucionário de Moçambique. 
É muito interessante ver como, muito antes de se tornar marxista-leninista em 1977, logo a seguir da sua fundação em 1962, a Frelimo declarava nos seus estatutos governar-se internamente segundo o "centralismo democrático". Isso tem a ver com discussões que podem parecer arcaicas hoje em dia, mas vale a pena refletir um pouco sobre o significado desta escolha. Com efeito, na tradição leninista, o centralismo-democrático, independentemente do que se pode pensar deste princípio, não é uma norma de funcionamento interna, mas externa: um direito completo de expressão das minorias dentro do partido, incluindo um direito à tendência e à fração, mas com disciplina quando se exprime para o exterior. Isso significa que os militantes conhecem internamente os termos dos debates, os pontos de vista das minorias e da maioria, e que a discussão é uma escola de politização. O "centralismo-democrático interno" apareceu, pelo menos como princípio, só depois, no período estaliniano: isto significa que um membro minoritário do Bureau político tinha que defender somente o ponto de vista da maioria perante os membros do Comité central, que não teriam, pois, conhecimento do debate no BP; e, se também aparecer diversidade no CC, só o ponto de vista maioritário seria explicado às bases, inclusive pelos membros minoritários do CC. As bases tinham, pois, uma visão monolítica do movimento no qual as divergências não eram vistas como fenómeno político, mas sim como traição, arrogância, intriga, tribalismo, etc. Este culto da homogeneidade não só não incluía o debate político como uma forma normal de governação, de ferramenta de politização e de cultura política, mas também transmitia uma visão de homogeneidade que era projetada à própria nação imaginada.

De facto, desde o início, existia uma conjunção entre o paternalismo autoritário da cúpula para com as bases, e um projeto de nação imaginada pela elite enquanto paradigma de modernização autoritária da população. Visto que as fronteiras coloniais não foram contestadas, essa nação imaginada ainda era para ser produzida dentro do espaço colonial cuja lógica espacial mantida era completamente 
a-nacional. Essa nação não era considerada como a lenta confluência (e permanência) das nações pré-coloniais (ou etnias, como quiser) numa nação de nações, mas como o mais ou menos rápido, segundo os contextos e estratégias políticas, desaparecimento das antigas identidades. Não queriam produzir uma identidade de identidades, mas, como dizia Samora Machel, "Para a nação viver, a tribo tem que morrer". É a problemática do "Homem Novo", um ser social sem raiz, ou com raízes folclorizadas ${ }^{26}$. Mas a minha pergunta é a seguinte: de onde vem este axioma, frequente em toda a África, mas exprimido de maneira bastante radical nos PALOPs?

Como vimos, este culto da unicidade que posso designar como sendo um desejo social existia antes da escolha do marxismo-leninismo e vem dos primórdios dos movimentos de libertação. $\mathrm{Ou}$ melhor, vem da trajetória social da formação das elites africanas (negras, mestiças ou brancas "filhos da terra"), no contexto particular de um colonialismo produzido por um capitalismo fraco e, no caso de Angola e de Moçambique sobretudo, um colonialismo de povoamento, de "pequenos brancos". Este tipo de colonialismo não deixa quase nenhum espaço social para a formação de uma elite africana. Ela é minúscula e ficou, principalmente na Guiné e em Moçambique, ainda mais enfraquecida pelas mudanças geopolíticas que surgiram na altura da passagem da primeira idade colonial para o capitalismo colonial, ocasionando mudanças de capital, de Cacheu para Bissau e da Ilha de Moçambique para Lourenço Marques, com a consequente marginalização dos antigos núcleos de elites crioulas vindos da primeira idade colonial escravista. Em Luanda, cidade que se manteve capital, as velhas elites crioulas continuaram a ser mais importantes mas recuaram perante o branqueamento da colónia. Em São Tomé, os fazendeiros mestiços, donos de roças, desapareceram aos poucos.

${ }^{26}$ Para uma análise mais detalhada da relação entre anticolonialismo, marxismo e questão nacional nos PALOPs, ver Cahen (2006). 
O que sobrou de elite foi reduzido a um estrato social muito estreito que não contem quase nenhum operário qualificado ou pequeno empresário. Não há relação direta com a esfera da produção. Como as conquistas portuguesas dos finais do século XIX e do início do século XX destruíram todas as grandes chefiaturas, e, como as mudanças de capital (Cacheu/Bissau, Ilha de Moçambique/Lourenço Marques) ou ainda o branqueamento intensivo (Luanda) marginalizaram as antigas elites, a nova elite tem poucas ligações sociais com os estratos sociais tradicionais. Ela ocupa os lugares inferiores do setor terciário (funcionalismo público, serviços comerciais, ferro-portuários, monitores escolares, enfermeiros auxiliares, alguns padres, etc.) onde está em concorrência direta com os "pequenos brancos". Essa elite vivia mais ou menos dentro ou nas margens imediatas do próprio aparelho colonial de estado, o seu imaginário era forjado por este posicionamento social, pela cidade colonial pacata dos anos quarenta e cinquenta do século XX, por uma colónia onde o Estado era o ator principal da economia, onde o sindicalismo (aberto só aos brancos, mestiços e negros assimilados) era corporativo, com um partido único, e onde existia um profundo desprezo pelas etnicidades africanas, etc. Essa elite manifestava um descontentamento mas era socialmente fraca. Ela precisava do Estado para a sua reprodução social e imaginava o futuro em função do que ela vivia. Por outras palavras, no final do período colonial, o seu imaginário político era muitas vezes conservador e pro-português, mas até podia chegar a ser anticolonial e separatista. Em contrapartida o seu imaginário social mantinha-se muito português, a não ser salazarista. Ela queria uma nação homogénea, com uma só língua, a sua - o português-, com cidades bem ordenadas, com um estado forte que fosse o ator principal da economia, um partido criador da nação una no espaço colonial mantido, com um sindicalismo e associativismo ligado ao partido na tarefa de "nacionalizar" e "modernizar" os habitantes. Ela queria uma nação unificada e modernizada que se afastasse o mais rapidamente possível da dita "tradição" -isto é, as relações 
sociais originais no seio do campesinato-para legitimar o espaço colonial mantido que socialmente e mentalmente era seu. O partido ou movimento que os seus segmentos anticoloniais iam produzir tinha que ser o cadinho da nação. Pois, como partido-nação, tinha que ser um partido único.

Este tipo de situação pode ser encontrado algures em África ou mesmo na Ásia, como na Indonésia. Mas no caso das colónias portuguesas, existia um outro fator: a impossibilidade de descolonizar pela negociação e o imperativo de fazer uma guerra longa contra uma ditadura obsoleta, no contexto internacional do pós-Segunda Guerra mundial. Pois, por um lado, a elite modernista do movimento de libertação queria um partido único, por outro lado, precisava de um instrumento ideológico para levar a cabo a guerra anticolonial. Assim se explica a escolha progressiva do marxismo-leninismo. Mas vejamos: não foi por a elite ter sido marxista-leninista que ela implementou uma cultura de partido único, a problemática tem que ser completamente invertida! Foi por ela querer um partido único que, num contexto particular de luta, encontrou no marxismo estalinizado -o dito "marxismo-leninismo"- a ferramenta discursiva de que precisava para o seu projeto de nação e de modernização autoritária. Aliás, também foi por isso que, vinte anos mais tarde, os mesmos partidos abandonaram, sem nenhum problema, sem dissidência interna, o mesmo "marxismo-leninismo". Isso não tira sinceridade aos que utilizaram tal discurso, porém não se tratava de uma identidade política, mas antes de uma ferramenta: seria possível imaginar o partido comunista cubano abandonar o marxismo sem crise interna? Neste caso, trata-se de facto de uma identidade. No caso da Frelimo e do MPLA num grau menor, a identidade encontrava-se muito mais do lado do projeto de nação homogénea do que do lado do marxismo. A questão da nação era o "fil rouge", como se diz em francês, o fio condutor de toda a evolução, que se vai mantendo, apesar das viragens políticas. 


\section{Trajetórias múltiplas}

Esse foi o quadro geral, mas não faria sentido parar por aqui devido às inúmeras nuances que existem. Cabo Verde, Guiné, Angola, Moçambique, São Tomé são países muito diferentes, com histórias africanas locais e regionais diferentes que, com certeza tiveram como ponto comum a experiência da colonização portuguesa, mas essa também foi muito diferente de um território para outro. É necessário lembrar que a colonização portuguesa, na totalidade da expansão territorial que representam hoje os PALOPs, não chegou a durar cem anos: esses países são muito mais africanos do que "ex-portugueses"

Vou empregar alguns exemplos dessas nuances e diferenças na cultura política. No entanto, vou começar mais uma vez por um ponto... comum, isto é, o fenómeno de geração política que não deve ser subestimado. Com efeito, a Frelimo, o MPLA, o PAIGC e o MLSTP fizeram parte da Confederação das Organizações nacionalistas das colónias portuguesas, a CONCP, cuja sede se encontrava em Rabat e depois em Argel. Foi uma espécie de Internacional dos combatentes das colónias portuguesas, que teve um papel importante no que toca às relações internacionais, mas também como cadinho de formação de um discurso político comum. Marcelino dos Santos, Mário de Andrade, Amílcar Cabral, foram pilares dessa organização que, em contrapartida, nunca integrou outras organizações tais como a FNLA ou a Unita angolana, a FLING guineense, o Coremo moçambicano, etc. Foi um cadinho de terceiro-mundismo de esquerda, contudo sem homogeneidade completa. Por exemplo, Amílcar Cabral sempre recusou reivindicar-se marxista, e isso provavelmente em razão da sua grande qualidade intelectual: o único marxismo que conhecia era o do Partido comunista português e o da União soviética que não achava adequados à situação guineense; no entanto, o modelo de "democracia revolucionária" que ele desenhara foi muito próximo, na prática ulte-

${ }^{27} \mathrm{Na}$ introdução ao seu livro, P. Chabal insiste com toda a razão neste aspeto (2002). 
rior, dos modelos implementados em Angola e em Moçambique, pelo menos na Guiné. A CONCP sobreviveu nos quinze primeiros anos de independência, na forma das Cimeiras dos Cinco, uma organização só destinada aos PALOPs e que não integrava nem Portugal nem o Brasil $^{28}$. No entanto, com as viragens neoliberais, essas cimeiras quase desapareceram com a formação da CPLP, a Comunidade dos Países de Língua Portuguesa, isto é, uma organização inter-estatal de ideologia muito diferente, a da lusofonia, que ainda provoca fortes discussões nos PALOPs, embora sejam mais hostis a Portugal do que ao Brasil ${ }^{29}$. Com as viragens neoliberais, o terceiro-mundismo de esquerda já não era útil enquanto ferramenta de unidade entre os cinco PALOPs, também porque eram doravante membros de organizações regionais africanas: a CEDEAO na África do oeste, a SADC na África austral, sem esquecer que Cabo Verde, a Guiné e São Tomé se juntaram à francofonia antes da formação da CPLP, e que Moçambique aderiu à Commonwealth também antes da formação da CPLP. A tendência, pois, vai no sentido de um distanciamento mútuo maior, em que a lusofonia representa uma supra-identidade leve, ao lado de muitas outras.

Voltando aos processos de trajetória social, também há diferenças importantes que tiveram repercussões na cultura política. Um exemplo notório é o caso do PAIGC binacional, que governou a República das Ilhas de Cabo Verde e a República da Guiné-Bissau de 1975 até novembro de 1980. Ora, o mesmo partido, com a mesma direção máxima e a mesma ideologia teve uma política completamente diferente nas duas entidades. No arquipélago, o PAIGC não fuzilou, torturou pouco, e tolerou um semanal católico que era de facto um

\footnotetext{
${ }^{28}$... nem o governo no exílio da República democrática de Timor-Leste. Moçambique albergava esse governo em exílio da Fretilin (Frente revolucionária de Timor Leste independente). Aliás, nem sempre houve homogeneidade dos Cinco em relação a Timor Leste, com tendências, na Guiné de Nino Vieira a estabelecer relações (e fazer comércio) com a Indonésia (também é de lembrar que o Brasil deixou de apoiar a Indonésia só depois da formação da CPLP).

${ }^{29}$ Sobre a ideologia da CPLP, ver Cahen (1997, 2003).
} 
jornal de oposição; no continente, o PAIGC foi muitíssimo violento, chacinando os antigos comandos negros do exército colonial sem processos, fuzilou publicamente chefes tradicionais, reprimiu severamente qualquer dissensão. Como se pode perceber isso? Provavelmente que a chave para a compreensão encontra-se nas diferenças consideráveis entre as duas sociedades. No arquipélago, a cúpula crioula do PAIGC estava em casa, na sociedade dela, correspondia mais ou menos à sociedade que era uma nação crioula. No continente, dentro de sociedades africanas habitualmente constituídas por formações sociais em linhagens, clãs, classes de idade, etnicidades, e com as lembranças ainda vivas dos antigos impérios africanos, a crioulidade não era a nação, mas um estrato social de elite. A direção do PAIGC, neste contexto, sentiu-se sempre frágil e isolada, usando pois a violência do fraco, até o golpe de estado de novembro de 1980 que pôs fim ao sonho de Amílcar Cabral de unidade Guiné-Cabo Verde (e que não acabou com a violência $)^{30}$. Um exemplo extraordinário dessas diferenças entre as culturas políticas é a situação prevalente, hoje em dia em Cabo Verde, com um presidente próximo da oposição e um Primeiro-ministro do PAICV. Seria, tal situação, simplesmente concebivel na Guiné, em Angola e em Moçambique?

Depois do golpe de novembro de 1980, o doravante PAICV manteve, no entanto, uma cultura política "africanista" no arquipélago, afirmando assim a africanidade do arquipélago e do seu povo. Ora, o que é interessante no caso caboverdeano é que o PAICV nunca conseguiu, ao contrário da Frelimo em Moçambique (Cahen 2010b), "preencher" por completo o imaginário nacional. Devido às emigrações na Holanda, nos Estados Unidos e algures, e também por causa da tradição dos "Claridosos" que se consideravam portugueses,

${ }^{30}$ A história dessas diferenças gigantescas de comportamento político do PAIGC em Cabo Verde e na Guiné Bissau parece-me ter sido insuficientemente pesquisada, embora houvesse algumas, mas poucas, publicações nos anos que seguiram o fim dos partidos únicos: por exemplo Koudawo \& Mendy (1996) e Evora (2004 - livro que é a publicação da tese de mestrado defendida em Brasília, 2001) 
embora de cariz particular ${ }^{31}$, e não africanos, sempre houve a tendência a separar a crioulidade da africanidade. Pode-se considerar que, pelo menos no início, o MpD (Movimento para a Democracia), que venceu as primeiras eleições livres em 1991, exprimiu essa cultura política não africanista de uma crioulidade autónoma ${ }^{32}$.

${ }^{31}$ O projeto dos "Claridosos" não era separatista, e isso não somente porque era proibido sê-lo: era mais a visão da "pequena pátria na grande pátria”, o que se pode traduzir por um autonomismo cultural. É de notar que este sentimento da "pequena pátria na grande pátria" foi caso corrente na Europa do século xix e da primeira metade do século xx, e quer reforçou o processo de produção dos Estados-Nação (a pequena pátria como forma de adesão e de entrada na grande pátria), quer esteve na origem do nacionalismo separatista (como no País Basco de França por exemplo). Pois deve-se evitar de qualificar teleologicamente essa fase como "proto-nacionalista" ou "pre-nacionalista", o que induz como axioma que a evolução devia ser a que foi de facto (o rumo à independência), a não ser uma traição. Há vários mestrados e teses em andamento sobre os Claridosos, mas sobre essa problemática do autonomismo pode-se já consultar trabalhos de Vítor Baptista Varela de Barros (2011) e de José Carlos dos (2006 [publicação da tese de doutoramento de 2002]).

${ }^{32}$ Utilizo o conceito de crioulidade como categoria de análise e não de sentido. Por exemplo, ao contrário dos Caboverdeanos, os Santomenses recusam-se a se auto-intitular "crioulos", o que não me impede analisar a formação social santomense como sendo uma formação principalmente crioula. É de sublinhar, no entanto, a larga plasticidade do conceito de crioulidade: como se sabe, no início, designava os brancos nascidos nas Índias ocidentais; depois designou também as elites mestiças (pardas); no Brasil, designou os descendentes negros de africanos escravizados, crioulo sendo sinônimo de forro (e até se falava em "colonos africanos"). Segundo as trajetórias históricas e as formações sociais, a crioulidade pode incidir sobre a totalidade da população e até formar uma nação com ou sem Estado (Cabo Verde, São Tomé, parte das Antilhas e das Mascarenhas), ou ficar limitada a estratos sociais específicos e geralmente de elite. Neste caso também, há situações diferentes: quando os Burmedjus da Guiné poderam se assumir como crioulos, os descendentes das antigas famílias de elite "angolana" do século xix ("angolana", isto é versus o gentio, os indígenas) geralmente recusam terminantemente o conceito, num contexto onde a crioulidade foi historicamente assimilada ao lusotropicalismo, ferramenta do colonizador contra o anticolonialismo. No entanto, do ponto de vista analítico, pode-se considerar como fenómeno de crioulidade os estratos sociais produzidos dentro ou nas margens imediatas do aparelho colonial de estado. Se se recusar, contextualmente, 
As crioulidades também tiveram um papel, pelo menos indireto, nas crises do MPLA. Vou utilizar só um exemplo pós-independência, o da tentativa de golpe de Estado de Nito Alves de Maio de 1977. O nitismo foi uma expressão populista de descontentamento da base social urbana do MPLA, historicamente oriunda do fenómeno dos "novos assimilados". Esse estrato social de africanos ainda oficialmente indígenas mas completamente urbanizados e que falavam português, se desenvolvera no pós-Segunda Guerra mundial ${ }^{33}$. A crise militar, política e social que conhecia Angola nos seus primeiros meses de independência provocou uma crítica acérrima aos privilégios da cúpula do MPLA, vista como a mão das antigas famílias crioulas ${ }^{34}$. A tentativa de golpe provocou 15 mortos, mas a repressão dela provavelmente 15000. Foi uma repressão feroz e indiscriminada que mergulhou a sociedade civil angolana no silêncio durante vinte $a_{0}{ }^{35}$. Como perceber isso, senão pelo reflexo de temor social por uma parte das antigas famílias crioulas que ficaram apavoradas pela ideia de perder o poder alcançado no Estado e no partido-nação que tinham criado? Depois, no decorrer da guerra civil, houve uma ten-

de utilisar o conceito de crioulidade para definir tais estratos sociais, ter-se-á que encontrar outra palavra com o mesmo significado... (Madeira-Santos 2007, Dias 1984). Sobre a instrumentalização muito mais recente da oposição angolanidade/ africanidade, veja Cahen (2001). Falo aqui somente dos estratos sócio-culturais e não das línguas crioulas ou krio.

33 Sobre o fenómeno dos "novos assimilados", veja Christine Messiant, (2006, publicação muito tardia da sua tese de doutorado de 1983] e Washington Santos Nascimento (2013).

${ }^{34}$ É bom insistir sobre o facto que, ao falar de crioulos e de crioulidade em África continental (pois excetuando Cabo Verde e São Tomé), não estou a referir-me à cor da pele, mas a um meio social africano específico, produzido dentro e nas margens imediatas do aparelho colonial de Estado. Um crioulo pode ser branco, mestiço, negro mas tem um estatuto sócio-cultural particular (veja nota 36).

${ }^{35}$ A pesquisa sobre a tragédia nitista fez progressos recentes mas continua a ser um campo de investigação para desenvolver. Veja principalmente, Dalila Cabrita Mateus (2009). 
tativa de se desfazer dessa crioulidade, com a imposição da menção da raça nos bilhetes de identidade para mostrar claramente que os mestiços -o que é diferente dos crioulos, numa confusão voluntáriaeram uma pequeníssima minoria e que o poder bem era negro. Hoje em dia, no capitalismo selvagem de Luanda, basta ver as capas das revistas de luxo destinadas à elite, para ver como esse ideal crioulo/ mestiço voltou com força: as mulheres das capas são quase sempre "mulatas", até o ponto de se poder falar de um ideal de mulatidade na elite. Já não é o branqueamento que os portugueses tentaram impor em tempos, mas trata-se de um "clareamento" óbvio ${ }^{36}$, o que não impede em nada que haja, às vezes, campanhas de demagogia "anti-claros" quando o poder político precisa.

Angola também é um país onde nenhum partido conseguiu preencher por completo o imaginário nacional, embora o contexto seja completamente diferente do de Cabo Verde, acima citado. Há fortes diferenças entre as culturas políticas do MPLA por um lado, e as da Unita ou da FNLA por outro, mais ligados à reivindicação da "autenticidade africana". É bom lembrar que o próprio nome da Unita (União nacional para a independência total de Angola) foi forjado para acusar o MPLA de não querer trazer uma verdadeira independência, uma vez que, segundo ela, se dispunha a entregar o poder aos "filhos dos colonos", isto é, aos mestiços. Hoje em dia, isso tudo ainda existe, mas está parcialmente esmagado pelo cilindro compressor do riquíssimo neopatrimonialismo do poder do MPLA. Podemos lembrar aqui a piada frequentemente contada em Luanda, sobre a melhor maneira de enriquecer: "Você cria um partido de oposição, assim depois, pode ser comprado".

Moçambique também é um caso interessantíssimo para perceber as diferenças de cultura política. Por razões históricas que não podemos detalhar aqui, a Frelimo foi o único movimento importante

${ }^{36}$ Sobre o ideal de "mulatidade" em Angola, ver a tese (em andamento) de Daniel Mbuta Miguel, Universidade de São Paulo, FFLCH. 
de libertação na colónia. Por isso, a Frelimo talvez tenha sido o caso mais bem sucedido de partido-nação além de partido único. Hoje em dia, é um partido hegemónico, mas continua a ser um partido nação ${ }^{37}$. É inconcebível para a elite da Frelimo perder o poder e, como o mostrou em 2000 (Cahen 2000), ela está pronta a um alto grau de violência para mantê-lo. Pode-se dizer que é porque a elite teme perder os privilégios económicos e sociais: é com certeza isso. Mas não só: há também um forte sentimento de "família", uma convicção de que foram eles que criaram este país e que, por conseguinte, esse poder pertence-lhes para sempre. É muito interessante ver como, nos textos da Frelimo, a oposição não é atacada simplesmente por ser a oposição, mas porque "põe em perigo a unidade nacional". Se a oposição, como tal (e não devido a algumas das suas propostas), põe em perigo a unidade nacional, é precisamente por que $n \tilde{a} o$ faz parte da nação, é um corpo estranho, estrangeiro, que o contexto internacional obrigou a aceitar mas que não tem legitimidade nacional. Como se pode ver, voltamos à importância gigantesca do mito nacional enquanto único meio de legitimar o espaço desenhado pelo colonizador. Pode ser visto de outra forma, até no vocabulário político popular que a Frelimo implantou no seio da população: quando o "povo" é evocado, não se trata da população, mas somente da parte da população que é membro do partido; o resto é designado por "elementos da população". Quando um responsável chega da capital para visitar uma aldeia, é apresentado como "aquele camarada que vem da nação", as pessoas tendo completamente integrado a ideia de que a "nação" é o lugar do poder, isto é, a cidade e em particular a capital.

${ }^{37}$ A crise politico-militar atual em Moçambique e os resultados das eleições autárquicas de novembro-dezembro 2013 em 53 vilas e cidades podem significar a perda dessa hegemonia. No entanto, embora pareça óbvio o fortalecimento de uma oposição urbana, na forma do MDM (Movimento Democrática de Moçambique, que é uma cisão da Renamo), não se deve esquecer que a maioria do eleitorado ainda vive no campo onde a maioria dos chefes tradicionais - que indicam para quem se deve votar- foram recuperados pela Frelimo depois do apoio de uma parte deles à Renamo durante a guerra civil. 
Penso que essa convicção que "Frelimo = nação" é importantíssima no facto que é inconcebivel para ela perder o poder.

\section{Três reparos}

Vou parar por aqui, fazendo só três reparos. O primeiro tem a ver com uma ideia frequente segundo a qual "não existem verdadeiros partidos políticos em África”. Seriam meras empresas político-económicas destinadas a alimentar a riqueza dos dirigentes, sem programa, com redes etno-clientelistas, etc. Se assim for, a maioria dos partidos políticos europeus e norte-americanos também não são verdadeiros partidos. A realidade é que os partidos africanos são muito frequentemente empresas político-económicas e têm uma cultura política-o que cria o sentimento de família que é indispensável à reprodução social de elites que, por sua vez, não são verdadeiras burguesias nacionais historicamente enraizadas. Penso que, nos PALOPs, pelo menos a Frelimo, o MPLA e o PAICV são bons exemplos duma forte cultura política.

O segundo reparo é que... a África lusófona não existe! Há estados de língua oficial portuguesa - o malogrado Jean-Michel Massa dizia "África lusógrafa" (Massa 1994)- mas trata-se de países que fazem parte, antes de tudo, das suas regiões africanas e estão inseridos na história delas. Insisto na importância em evitar sobrestimar o papel da língua colonial na formação das identidades. Ela tem o seu papel, mas é um "marcador identitário" entre muitos outros. Não é de admirar, pois, que encontramos, a nível das culturas políticas, diferenças tão numerosas quanto as semelhanças.

O último reparo é relativo ao subtítulo deste artigo, "Um ponto de vista 'pós-póscolonial'". Comecei essas linhas a criticar as teorias póscoloniais, por reificarem as heranças, serem incapazes de desenvolver análises globais das sociedades e dos Estados ao 
ficar nos "fragmentos" sociais; por generalizarem -quando fazem sentir a influência pós-moderna-a recusa das grandes narrativas; por preferirem a análise textual à da realidade das relações sociais; por despolitizar a crítica política anticolonial numa mera crítica epistemológica póscolonial, etc. No entanto, "pós-pós" não é sinónimo de "anti" e deve-se evitar de deitar fora o bebé juntamente com a água do banho ${ }^{38}$. Parece que o período de sucesso das teorias póscoloniais já passou no mercado académico. Mas será por isso que a atenção às modernidades alternativas, ao "político pelo baixo" desenvolvido pelos subalternos, às epistemologia dos saberes ${ }^{39}$, perdeu as suas relevâncias? A resposta é claramente negativa, mas é preciso desenvolver essas análises diversificadas voltando a utilizar conceitos universalistas, e evitando o relativismo cultural. Nos PALOPs, apesar do uso frequentemente indiscriminado da epitete "pós(-)colonial" em artigos e livros, precisamos ainda de uma atenção subalternista para não "autonomizar" ou "textualizar" demais a análise das elites, dos partidos e dos líderes.

\section{Referências}

ANJOS, José Carlos Gomes dos. Intelectuais, literatura e poder em Cabo Verde: Lutas de Definicao da Identidade Nacional. Porto Alegre, EdUFRGS, 2006, 272p. ASHCROFT, Bill, Gareth Griffiths e Helen Tiffin. The Empire Writes Back: Theory and Practice in Post-Colonial Literature. Routledge, 1989, 256p.

BALANDIER, Georges. "La situation coloniale. Approche théorique." Cahiers internationaux de sociologie (Paris: Presses universitaires de France), XI, 1951: 44-79.

38 ... o que faz obviamente Jean-François Bayart no seu brilhante mas demais polémico ensaio (2010). Para uma crítica detalhada, preferi: Vasant Kaiwar (2013) e Vivek Chibber (2013).

39 ... o que não quer dizer "epistemologia do Sul" - Sul sendo um conceito neoliberal, culturalista e reificador que não trouxe nenhum progresso analítico ao de “terceiro-mundo" (Santos \& Meneses 2010). 
BARROS, Vítor Baptista Varela de. "Império, Colonialismo e Pós-colonialismo: os jardins da memória e as melancolias da crítica histórica contemporânea." Estudos do Século $X X$ (Coimbra), nº11, 2011, pp.301-317.

BAYART, Jean-François. Les études postcoloniales. Un carnaval académique. Paris: Karthala, 2010, 132 p.

BOWEN, Merle L. The State against the peasantry. Rural Struggles in Colonial and Postcolonial Mozambique. Charlottesville: University Press of Virginia, 2000, 256p.

CAHEN, Michel. “À la recherche de la défaite. Notes sur une certaine historiographie de la 'révolution' et de la 'contre-révolution', au Mozambique et sans doute ailleurs.” Politique Africaine (Paris: Karthala), dezembro de 2008, n²112, pp. 161-181.

CAHEN, Michel. "Des caravelles pour le futur? Discours politique et idéologie dans 1' 'institutionnalisation' de la Communauté des pays de langue portugaise." Lusotopie (Paris: Karthala), vol. IV, 1997, pp. 391-433

CAHEN, Michel. "Il n'y a pas d'État néo-patrimonial”, in Dominique Darbon (ed.), Le comparatisme à la croisée des chemins. Autour de l'œuvre de Jean-François Médard, Paris: Karthala 2010a, 252p., pp.113-140.

CAHEN, Michel. "Lutte armée d'émancipation anti-coloniale ou mouvement de libération nationale? Processus historique et discours idéologique. Le cas des colonies portugaises, et du Mozambique en particulier." Revue Historique (Paris: PUF), CCCXV/1 (637), Janeiro de 2006: 113-138.

CAHEN, Michel. "Que faire du Portugal quand on est africain?" in "Le Portugal et l'Atlantique." Arquivos do Centro cultural Calouste Gulbenkian, Paris-Lisboa: XLII, Dezembro de 2001, pp.53-70).

CAHEN, Michel. "What Good is Portugal to an African?" in Stewart LLOYD-JoneS \& António Costa Pinto, The Last Empire. Thirty Years of Portuguese Decolonization. Bristol (R.-U.), Portland (Or.), 2003: 83-98.

CAHEN, Michel, “Mozambique: l'instabilité comme gouvernance?" Politique Africaine (Paris: Karthala), n80, Dezembro de 2000: 111-135.

CAHEN, Michel. "Mozambique: une impossible alternative dans la culture politique?” in António Romão, Joaquim Ramos Silva \& Manuel Ennes Ferreira, Homenagem ao Professor Adelino Torres. Lisboa-Coimbra: Almedina, 2010, 842p.: 601-649.

CHABAL, Patrick. "What is Africa? Interpretations of Post-Colonialism and Identity." in Victor Pereira da Rosa \& Susan CAstillo (eds), Pós-Colonialismo e identidade. Porto: Universidade Fernando Pessoa, 1998: 209-226. 
CHATTERJEE, Partha. “After Subaltern Studies.” Economic and Political Weekly (Mumbai: Sameeksha Trust), $1^{\circ}$ de setembro, 2012, XLVII (35): 44-49.

CHIBBER, Vivek. Postcolonial Theory and the Specter of Capital. Londres-New York: Verso, 2013.

COSTA, Iná Camargo. "O fardo pós-colonial." Discurso Editorial (São Paulo), 2001, v. 1, p. 238-239.

DIAS, Jill Rosemary. "Uma questão de identidade: respostas intelectuais às transformações económicas no seio da elite crioula da Angola portuguesa entre 1870 e 1930." Revista internacional de estudos africanos, Lisboa: IICT, vol.I, Janeiro-Junho de 1984: 61-94.

DINERMAN, Alice. Revolution, Counter-Revolution and Revisionism in Postcolonial Africa. The case of Mozambique, 1975-1994. Abingdon (RU): Routledge, 2006, 396p.

EVORA, Roselma. A abertura política e a transição para a democracia em Cabo Verde. Mindelo (Cabo Verde): Spleen, 2004, 134p.

GUHA, Ranajit. Elementary Aspects of Peasant Insurgency in Colonial India. Delhi: Oxford University Press, 1983.

HALBWACHS, Maurice. Les Cadres sociaux de la mémoire. Paris: Albin Michel, 1994, 374 pages. [1a ed. 1925]

KAIWAR, Vasant. L'Orient postcolonial. Sur la "provincialisation" de l'Europe et la théorie postcoloniale. Paris: Syllepse, 2013

KOUDAWO, Fafali \& Peter Karibe Mendy. Pluralismo politico na Guiné-Bissau. Uma transição em curso. Bissau: INEP, 1996, 164 p.

LÖWY, Michael. As Aventuras de Karl Marx contra o Barão de Münchhausen. São Paulo: Cortez, 1987.

MADEIRA-SANTOS, Catarina. "De antigos conquistadores a angolenses. A elite colonial de Luanda e a cultura das Luzes, entre lugares de memória e conhecimento científico." Revista de História da Cultura e das Ideias Políticas, Lisboa: Universidade Nova de Lisboa, Centro de História da Cultura, número especial: "Cultura Intelectual das Elites coloniais”, 2007.

MASSA, Jean-Michel, “Lusophonie-Lusographie.” Lusotopie (Paris: L'Harmattan), I (1-2), 1994, 268-274.

MATEUS, Dalila Cabrita. Purga em Angola. Lisboa: Textos Editores, 2009, 206p.

MERLE, Isabelle. "Les Subaltern Studies. Retour sur les principes fondateurs d'un projet historiographique de l'Inde coloniale.” Genèses (Paris), 2004, III(56): 131-147. 
MESSIANT, Christine. 1961. L'Angola colonial, histoire et société. Les prémisses du mouvement nationaliste. Basileia (Suiça): P. Schlettwein Publishing, 2006, 444p. MESSIANT, Christine, L'Angola postcolonial.1. Guerre et paix dans démocratisation. 2. Sociologie politique d'une oléocratie, Paris: Karthala, 2008-2009, 420p.+432p., etc. MONTEIRO, Maria Conceição. Leituras contemporâneas: interseções nas literaturas de língua inglesa: feminino, gótico, pós-moderno, pós-colonial, Rio de Janeiro: Caetés, 2009, 131p., etc.).

MONTEIRO, Paula. “O projeto pós-colonial.” Jornal de Resenhas (São Paulo), p. 9, n.53, 1999.

MORIER-GENOUD, Éric \& Michel CAHEN. "Portugal, Empire and Migrations. Was there ever an autonomous Portuguese imperial space?" in Éric Morier-Genoud \& Michel Cahen (eds), Imperial Migrations. Colonial Communities and Diaspora in the Portuguese World. Basingstoke (R.-U.): Palgrave MacMillan, novembro de 2012, 368p.: 1-28.

NASCIMENTO, Washington Santos. "Gente do mato: novos assimilados em Luanda (1926-1961)". Tese de doutorado em história, São Paulo: USP-FFLCH, 2013, 235p.

PATRICK CHABAL et alii. A History of Postcolonial Lusophone Africa. Londres: Hurst, 2002, 339p.

QUIJANO, Aníbal. “Colonialidad y modernidad/racionalidad.” in Heraclio BonILLA (ed.), Los Conquistados. 1492 y la Población Indígena de las Américas, Bogotá: Tercer Mundo Editores, 1992b: 437-447.

QUIJANO, Aníbal. “Colonialidad y modernidad/racionalidad.” Péru Indígena (Lima) XIII(529), 1992a

ROSA, Victor Pereira da \& Susan CAstillo (eds). Pós-Colonialismo e identidade. Porto: Universidade Fernando Pessoa, 1998, 226 p.

SANTOS, Boaventura de Sousa \& Maria P.MENESES. Epistemologias do Sul. São Paulo: Cortez Editora, 2010, 637p.

SOUZA, Lynn Mário Trindade Menezes de. O rato que ruge: aspectos de discurso literário pós-colonial em língua inglesa. Tese de doutoramento, Niterói: 1992

SPIVAK, Gayatri C. “Can the Subalterns Speak?” in Cary NELSON \& Lawrence GROSSBERG, Marxism and the Interpretation of Culture. Chicago: University of Illinois Press, 1988, p. 271-315.

SPIVAK, Gayatri C. Pode o subalterno falar? Belo Horizonte (MG): Ed. Universidade federal de Minas Gerais, 2010, 133p. 
MICHEL CAHEN é um historiador francês, pesquisador do Centre $\mathrm{Na}$ tional de la Recherche Scientifique, especialista da colonização portuguesa contemporânea em África e da evolução dos novos Países africanos de língua oficial portuguesa. Foi fundador da revista Lusotopie, uma revista trilingue (português, francês, inglês) de análise política dos espaços oriundos da colonização e da história portuguesa (publicada de 1994 até 2009). Além disso, interessa-se por temáticas gerais tais como marxismo e nacionalismo, etnicidade e democracia, colonialidade e subalternidade. Entre seus principais e mais recentes trabalhos publicados: Os outros. Um historiador em Moçambique, 1994, Basileia (Suisse), P. Schlettwein Publishing Foundation, 2003, 230p.; "Luta de emancipação anti-colonial ou movimento de libertação nacional?", Africana Studia (Porto), VIII, 2005: 39-67; "Lusitanidade e lusofonia. Considerações conceituais sobre realidades sociais e políticas", Plural Pluriel. Revue des Cultures de langue portugaise, 2010, 7; Le Portugal bilingue. Histoire et droits politiques d'une minorité linguistique: la communauté mirandaise, Rennes, Presses Universitaires de Rennes, 2009, 212p.; "Indigenato before race? Some proposals on Portuguese forced labour law in Mozambique and the African Empire (1926-1962)", in Francisco Bethencourt \& Adrian Pearce (eds), Racism and Ethnic Relations in the Portuguese-Speaking World, Londres, British Academy / Oxford, Oxford University Press, 2012: 149-171; co-ed. com Éric MorierGenoud, Imperial Migrations. Colonial Communities and Diaspora in the Portuguese World, Basingstoke (R.-U.), Palgrave MacMillan, 2012, 368p; "Is "Portuguese-speaking" Africa Comparable to "Latin" America? Voyaging in the Midst of Colonialities of Power", History in Africa: A Journal of Method (African Studies Association, Cambridge Journals), XL(1), 2013: 5-44.

Université de Bordeaux, Sciences Po Bordeaux, Unité mixte de recherche n०5115 "Les Afriques dans le monde”, CNRS/Institut d'études politiques deBordeaux, <m.cahen@sciencespobordeaux.fr>.

Enviado em 20 de agosto de 2015

Aprovado em 30 de outubro de 2015 